\title{
Study on Brain Drain in Rural Areas from the Perspective of Rural economic Revitalization - An Empirical Analysis Based on the Questionnaire Data in Village B, County A
}

\author{
Ye Haiyan ${ }^{1}$, Yu Shiwan ${ }^{2}$ \\ ${ }^{1}$ Organization: Software Engineering Institute of Guangzhou (SEIG) \\ ${ }^{2}$ Organization: Software Engineering Institute of Guangzhou (SEIG), Corresponding author.
}

\begin{abstract}
In the context of global economic innovation and low-carbon development, Rural Development is bound to take the road of rejuvenation, The core of the road of rejuvenation is the rejuvenation of talents,

The key to the rejuvenation of talents is how to bring back talents。 This paper studied the status and causes of brain drain in Village B, County A through data statistics and interview data organization based on an empirical analysis of the questionnaire data of its brain drain, and analyzed the problem of brain drain in the village in terms of the family structure, the construction of infrastructure, guiding policies of the government and the gap between urban and rural economic incomes, thus identifying factors which restrict rural talent revitalization. The study has found that the small number of jobs provided by the government, insufficient functioning of the Party and the government and the neglect of rural talent market planning and construction are the three main causes of brain drain.
\end{abstract}

\section{Introduction}

As China continues to grow stronger, its urban construction has become more and more systematic and standardized, and the phenomenon that rural development cannot keep up with urban development has also emerged in China. Young people born in the 1990s are unwilling to develop in the countryside, including not only those in urban areas, but also those born and growing up in the countryside. College students from rural areas who have a higher level of education are reluctant to return to their hometowns for development because there are better opportunities and higher salaries in cities. Those at a lower level of education would rather serve as "couriers" or "men for takeout" in big cities or "workers" who are more willing to work in factories of towns other than doing farm work in villages.

County A has always been a "golden channel" connecting Shanghai, Zhejiang and Fujian, with rich and diverse ecological resources such as mountains, basins, deep valleys, lakes, oceans and plains. It has been known as "the best resort in Lingnan and the ancient Penglai along the coast of Yinghai Sea" since ancient times. However, it is exactly the diversity of the ecological environment that leads to uneven population distribution. The connection of villages is blocked by the natural environment, making the traffic and logistics obstructed.

Village B is one of the remote villages in County A, which is often overlooked in the map. It has always been a small village relying on the mountains for development since ancient times. The village has been self-sufficient and rarely open to the outside world. The mountain road connecting the village and the outside was constructed by a few people who had worked hard outside a few years ago. With the continuously accelerated development of urban economy since the generation of grandparents, most people have been unwilling to stay in the village and rely on the nature for living, and instead, they expect to work outside, resulting in the smaller number of residents in the small and closed village as well as year-by-year serious brain drain. The county government also helped the village in the reform and development through financial assistance and achieved some results after the implementation of rural revitalization strategy by the Party Central Committee. However, giving people fish is not as good as teaching people how to fish. Economic assistance is not a long-term effective means. To be revitalized, Village B needs to explore a sustainable reform path appropriate to its characteristics. The role of "people" is bound to be indispensable for the healthy and sustainable development of a village. People are labors who can create wealth, produce goods and promote rural development. Therefore, all the conditions required for rural revitalization are based on people. Talent revitalization has become a key point of rural revitalization, so we must attach importance to brain drain in rural areas.

Following the national policy, the government of 
County A has made a suggestion on the introduction of talents. The talent revitalization policy requires certain time and space to benefit each village. However, Village $\mathrm{B}$ is neither poor nor rich. It is in a very embarrassing position, which means it has not only self-sufficiently wealthy villages driving the economic development of surrounding small villages above, but also down-and-out unknown villages relying on government subsidies and relief from large villages below. It has become a neglected village. Therefore, it has very limited resources available and limited allocation of material and financial resources. Its problem of brain drain is becoming more and more serious year by year, resulting in its increasing emptiness and downfall. Therefore, Village B is taken as the object of study on population loss. The practical significance is that this study can enrich and improve the incentive policy for talent return from the perspective of rural revitalization, ease the current situation of population loss and village emptiness and improve the employment environment of talents, thus alleviating the problem of labor shortage there to a certain extent.

\section{Literature review}

Studies on rural development in Japan have shown unprecedented growth following the formal proposal of "rural revitalization strategy" at the $19^{\text {th }}$ National Congress of the Communist Party of China in 2017. Studies are mainly divided into two aspects. One is the analysis on the cause, background and effect of Japan's rural revitalization movement by macro and micro means. For example, Li and Liu (2020) studied and judged rural problems in different periods and the production, implementation and effect of rural revitalization practices and legal policies in the Mirror of Japanese Rural Revitalization from the perspective of Japan's economic and social development. They believed that the effective development of rural revitalization in Japan was due to the enactment of appropriate and targeted legislation during the rural revitalization movement, which provided a legal guarantee for the stable implementation of various rural revitalization measures; socially, the National Farmers Federation had become a powerful organizational guarantee for the successful promotion of rural revitalization; besides, the government had comprehensively promoted rural revitalization, leading to market-driven endogenous power and vitality; in addition, the unified household registration system and factor market for urban and rural areas had also facilitated urbanrural integration to a certain extent. ${ }^{[1]}$ The other is the analysis on each measure taken in Japan's rural revitalization movement, assimilation of its essence and rejection of its dross and application of such measures in the Chinese countryside with Chinese characteristics. For example, Xu (2018) focused on the role that the government and society played in rural revitalization, the implementation of a series of measures around the background of rural revitalization and their effects while drawing lessons from Japan's rural revitalization movement and concluding a set of measures suitable for China's own rural revitalization strategy in the Experience of and Reference from Japan's Rural Revitalization Movement. ${ }^{[2]}$

(I) Study on national conditions and policies. In the Opinions of the Central Committee of the Communist Party of China and the State Council on the Implementation of Rural Revitalization Strategy (2018), the Chinese government has insisted on working out solutions to issues relating to agriculture, rural areas and farmers as a top priority of the work of the whole Party, continued to enhance the policy of strengthening agriculture, benefiting farmers and raising rural living standards, promoted agricultural modernization and new rural construction solidly and deepened rural reforms comprehensively under the strong leadership of the Party Central Committee with General Secretary Xi Jinping at the core since the $18^{\text {th }}$ National Congress of the Communist Party of China, making historic achievements in agricultural and rural development and providing important support for the comprehensive creation of a new situation in the cause of the Party and the country. ${ }^{[3]}$ During the two sessions in 2018, General Secretary Xi Jinping clearly put forward the scientific thesis of "five major types of revitalization", namely "revitalization of rural industry", "cultural revitalization", "organizational revitalization", "ecological revitalization" and "talent revitalization", when the Shandong delegation participated in the deliberation. Although talent revitalization is the last type mentioned, it cannot be underestimated as other development needs are inseparable from the most important talent revitalization. It is imperative to strengthen rural talent revitalization and build a team of rural talents with strong competitiveness.

(II) Study on population mobility. China has always been a large country with vast land. Population mobility has been an inevitable phenomenon since ancient times, which will inevitably affect the rural population structure and lead to changes in the rural social structure. In the study of rural population mobility, Pu and Sun (2018) believed that the realization of rural revitalization should rely on not only "local talents" but also the introduction of outstanding talents and the return of rural elites from all walks of life. ${ }^{[4]}$ Qian and Wang (2019) believed that the current social talent flow would lead to deviations in the concept of local talents and that urbanization had made the concept of cities deeply rooted in the heart of people, but the traditional rural concept had gradually faded. ${ }^{[5]}$ Zhou (2020) argued in the Impact of Population Mobility on Rural Social Governance and Countermeasures that for villages into which people flowed, population mobility would complicate rural social governance and cause exclusiveness; for those with population outflow, the populations were generally aging and the loss of young and middle-aged people would lead to an increasingly serious issue relating to the education for the elderly in rural areas. ${ }^{[6]}$

(III) Study on educational revitalization. According to the study of the second population mobility, we can recognize the impact of population mobility on educational resources, which is the root cause of the gradual shortage of educational resources in rural areas. How to cultivate rural talents seems especially important 
under the current situation of serious rural area brain drain. Therefore, how to increase the proportion of educational revitalization in rural revitalization is also the research direction of many scholars. Liu and Xie (2018) believed that the current education system was limited and that diligent and studious talents cultivated in rural areas were ultimately exported to cities, which made rural areas lack talents even worse. ${ }^{[7]}$ Wang and Chen (2018) believed that only by cultivating new professional farmers through school-village cooperation can we institutionalize, standardize and professionalize rural education, improve farmers' professional outlook, remove urban and rural talent barriers and promote the dual-track flow of urban and rural talents. ${ }^{[8]}$ Wang and $\mathrm{Hu}(2021)$ considered that China's training mechanism for rural vocational education talents was incomplete and that a new professional farmer team must be constructed so as to achieve the revitalization of rural industry.

\section{Research design}

This survey aimed at villagers in Village B. The questionnaire included 12 questions in total and was in the anonymous form to ensure its fairness and authenticity.

First, according to the basic information of samples, in terms of gender, 80 males and 86 females participated in the survey, accounting for $48 \%$ and $51 \%$ of the total samples respectively. In terms of age, the survey was dominated by young people aged $18-25$, accounting for $69 \%$ of the total samples, followed by middle-aged people aged 26-30 and 31-40, accounting for $10 \%$ and $12 \%$ respectively. In terms of education level, the survey mainly involved undergraduates and junior college students accounting for $83 \%$ of the total samples.

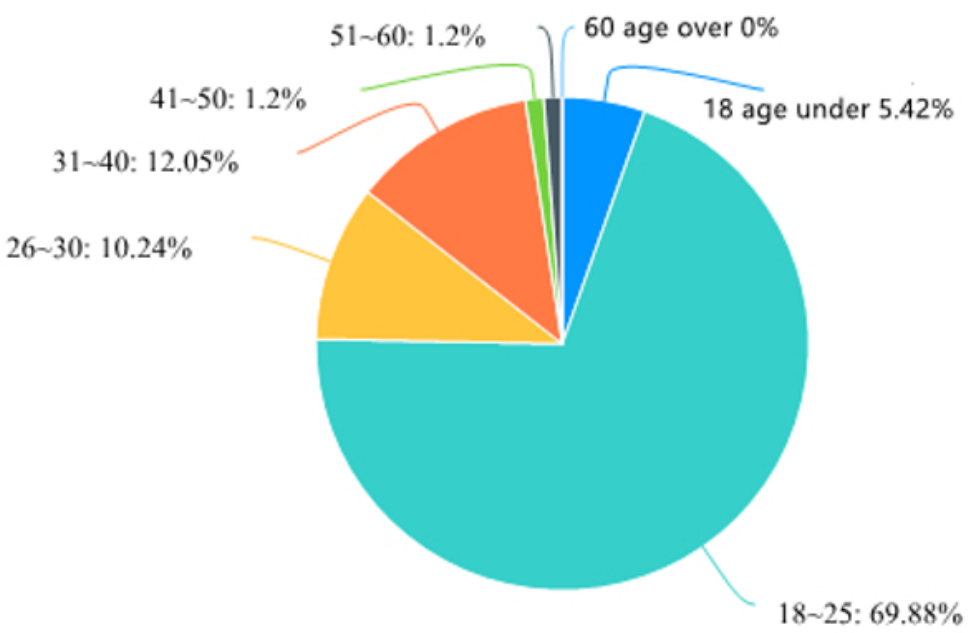

Figure 1 Age distribution

Second, an analysis is conducted on the problem of population loss, the family structure, the construction of infrastructure, guiding policies of the government and the gap between urban and rural economic incomes in Village $\mathrm{B}$ in each dimension of the survey data so as to identify factors that restrict the revitalization of rural talents.

In terms of the importance of the village, villagers are highly dependent on the village. $65.66 \%$ of the villagers considered the village important or even very important to them. Moreover, as many as $72.29 \%$ of the villagers were willing to stay in the village provided that rural revitalization played a substantial role and the future village was more attractive than cities.

\subsection{Analysis of the current situation of brain drain in Village $B$}

(1) Failure in comprehensive coverage of basic educational facilities

Education has always been a right and obligation of every child. The spread of nine-year compulsory education in China aims to make every child have the habit of reading and improve the basic quality of the people. However, the current rural education is incomplete and the basic educational measures in each village have not been fully implemented. When will education benefit every rural child? According to the questionnaire, only $17.47 \%$ of the villagers believed that the basic educational facilities in the village had fully met the educational needs of rural children; as many as $74.7 \%$ of the villagers deemed that the village school only met the most fundamental educational needs and that children in the village had to go to the county a few kilometers away for further education; only $7.83 \%$ of the villagers believed that the educational measures in the village could not meet the educational needs of rural children at all. According to interviews, it has been learnt that there is an elementary school in Village B, to which most of the children in the village go for study. However, children need to go to County A for studying in junior and senior high schools and even colleges after graduation from the elementary school. To pursue for better educational resources, they have to go to the prefecture-level city or even provincial capital for study. Besides, the elementary school in the village does not have adequate educational resources. The teaching building has a long history and desks and chairs in classrooms are relatively outdated. There are few teachers in the school, many of whom teach students in 
several grades. It has been learnt that villagers in the older generation only received elementary education and only village cadres received more education. Therefore, they have not attached great importance to the education of the younger generation. Most children in the village chose to work in society after finishing the nine-year compulsory education. Therefore, it is required to improve rural educational facilities so that children in rural areas do not have to walk a few kilometers to the county for study and every rural child can receive education without considering any factor, thus improving the overall quality of villagers and making talents available for villages. It can be seen that education is an important breakthrough for the revival of talents in every village.

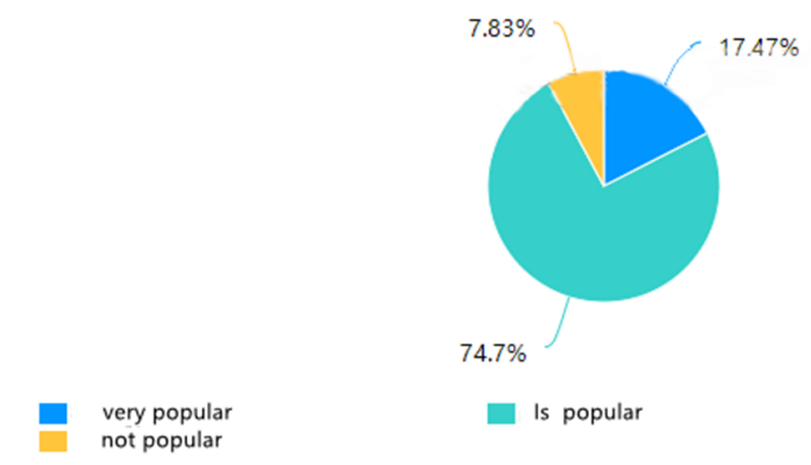

Figure 2 Villagers' understanding of the level of education popularization

(2) Flow of young laborers into cities and towns and lack of rural laborers

When villagers were asked whether their family members worked outside, only $28.92 \%$ of the families had no members working outside, $28.31 \%$ had members working in the county, $40.36 \%$ had members working in a prefecture-level city and $31.33 \%$ had members working in first- and second-tier cities.

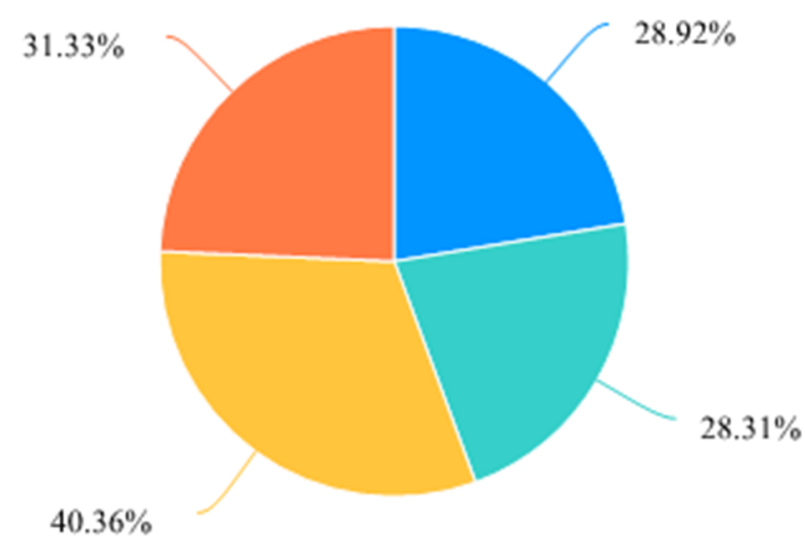

Figure 3 Situation of members of rural families working outside

When villagers were asked about the reason for working outside, the dominant reason was the high income in the city, which was chosen by as many as $60.9 \%$ of the respondents; the second reason was the lack of better development opportunities in rural areas, chosen by $57.89 \%$; working outside for enriching the experience and the inconvenience of rural life were also the reasons, chosen by $37.59 \%$ and $35.34 \%$ respectively. 
High urban income

Go out and see the world

Country life is inconvenient

countryside less opportunities

influenced by others

$14.29 \%$

for family reunion

others

$6.77 \%$

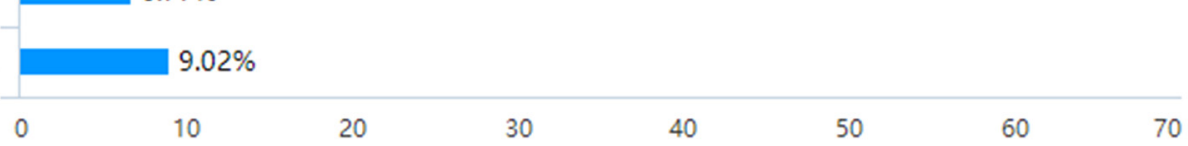

Figure 4 Analysis of the reasons for villagers working outside

Most seriously, when it comes to what type of families was dominant in the village, $85.54 \%$ of the villagers thought that the current type of rural families was that young and middle-aged people worked outside and the elderly and children were left in the village. This indicates that it has become a basic consensus of villagers that rural young and middle-aged people work outside.

\begin{tabular}{|c|c|c|}
\hline \multicolumn{1}{|c|}{ option } & & proportion \\
\hline all family is in the countryside & 24 & $14.46 \%$ \\
\hline Young work outside, elderly and children in the village & 142 & $85.54 \%$ \\
\hline The number of valid fill in this & 166 & \\
\hline
\end{tabular}

Figure 5 Composition of rural families considered by villagers

In summary, there are many rural families with members working outside in Village B at this stage, which is accompanied by serious rural brain drain. Moreover, villagers with deeply rooted traditional concepts believe that cities can provide better employment development opportunities, wider employment platforms and higher incomes than the countryside. Therefore, villages need to understand the root cause why villagers go out to work and meet their employment needs so as to retain talents and make talents available in the countryside.

(3) Incomplete rural infrastructure and little room for employment development
According to the questionnaire survey, $51.2 \%$ of the villagers believed that incomplete educational measures in the countryside were the reason for the flow of rural population into cities; $54.82 \%$ deemed the low income from farming as the reason; as many as $74.7 \%$ attributed it to the little room for employment development in villages and towns; $60.24 \%$ to the lower economic level of rural areas compared to cities; $30.12 \%$ to the few national policies on rural employment; only $10.84 \%$ and $28.92 \%$ to the poor rural ecological environment and the inconvenient rural transportation.

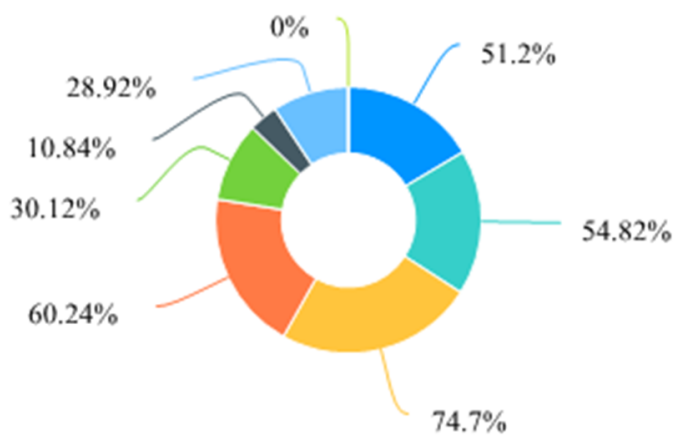

Figure 6 Analysis of reasons for the flow of rural population into cities 
Therefore, it is extremely urgent to play the role of the "visible hand" of the government to provide a good employment platform for rural talents and create a good employment environment to increase the income of rural residents returning home and reduce the urban-rural gap, and improve rural infrastructure to prevent the brain drain.

(4) Long-term vacancies for village cadres and low effectiveness of village management

According to the questionnaire, as many as $68.07 \%$ of the villagers considered that population loss would lead to the lack of rural labors; $59.04 \%$ thought that it would make collective affairs of the village left unattended; $53.01 \%$ thought that it would lead to village desolation and $52.41 \%$ believed that it would result in the weakening of interpersonal relationships.

This indicates that villagers attach great importance to the impact of the brain drain on the village. After all, the hometown is the home of their own souls. Every villager is willing to make contributions to his/her hometown, but the construction progress of the hometown cannot keep up with the pressure brought by life. Therefore, many villagers have to leave their native places. Meanwhile, village affairs are unattended as many villagers leave the village and only those who are old and weak, women and children stay at home. Only the few familiar people take part in the election for grass-roots cadres. Some positions remain vacant for a long time and village management fails to progress and develop effectively. Village cadres play a leading role in the village. If no one wants to be cadres, the structure of talent teams for rural construction cannot be expanded. Without a long-term strategic plan for rural construction, rural areas will only stagnate and even be more and more desolate and the talent gap will only increase. Therefore, it is necessary to improve the rural talent construction team and give full play to the leadership and exemplary role of village cadres so as to plan the current construction direction and future development needs of the village and guide the return of talents.

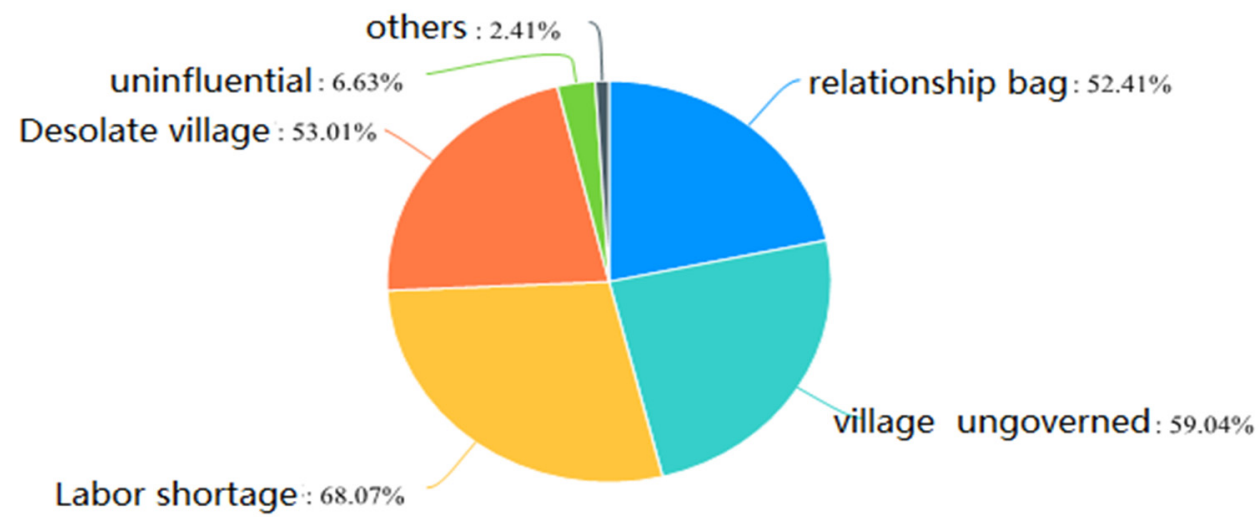

Figure 7 Impact of population loss

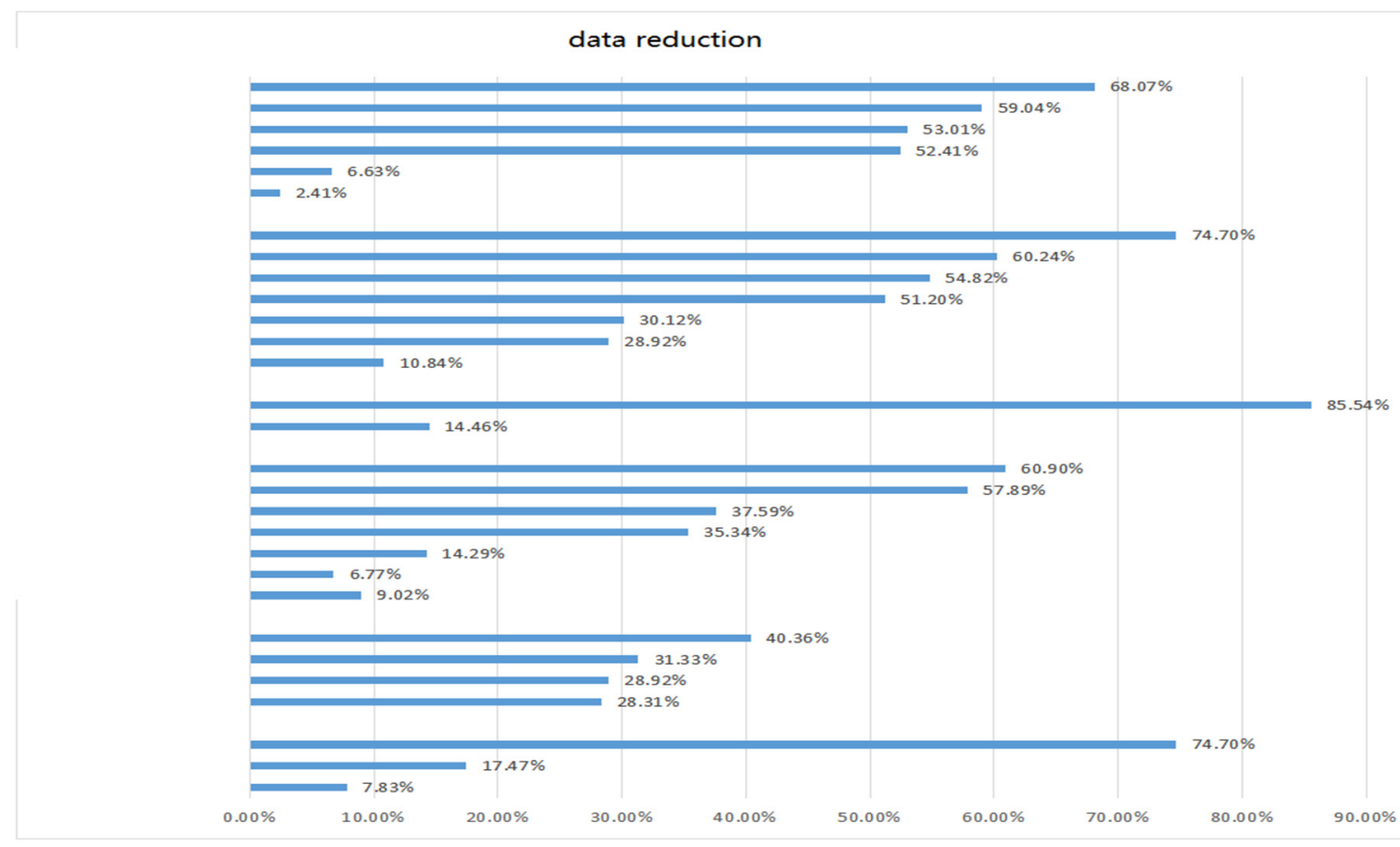

Figure 8 Data summary 
As shown in Figure 8, villagers are generally aware that young and middle-aged villagers working outside and the lack of labor in the village will make the village lacking in cohesion and more and more declining. However, most villagers still choose to go out for work whenever there is a chance, indicating the lack of attractiveness of the countryside and the large gap between urban and rural areas. Compared with the countryside, cities and towns can give young people more space for development and have a more mature talent environment. Therefore, for rural revitalization, we must first know how to attract and retain talents, narrow the gap between urban and rural areas and change the rural talent environment. This is the fundamental way to curb the loss of talents.

\section{Analysis on the causes of brain drain in Village B}

\subsection{Few jobs provided by the government and low selectivity for villagers}

Following the rural revitalization strategy put forward by the $19^{\text {th }}$ National Congress of the Communist Party of China, the government of County A has also given subsidies to employees of local enterprises and provided a lot of financial subsidies to farmers in the village, but with little effect. According to interviews, it can be learnt that there are few companies near the village, which are mostly tea factories, resulting in little room for selection. Meanwhile, there is a lack of systematic salary and welfare system and room for promotion. According to the questionnaire data, $85.54 \%$ of the villagers believed that the structure of the village was that young and middleaged people worked outside and only the elderly, women and children stayed at home. There is a serious loss of youth labor in the village. The labors left lack the related skill and quality and are incompetent for high-intensity work. Therefore, the development of Village B is greatly restricted. Compared with cities, rural areas have poor sanitary conditions, making it difficult to attract urban talents, which leads to rural hollowing and difficulty in rural economic development.

\subsection{A large number of villagers but a small number of talents and a lack of talent advantages.}

There are very few talents in Village B at present. It is difficult even for the whole village to cultivate a rural college student who is willing to stay in the village for construction. The urban "siphonic effect for talents" has always been acting on the countryside. Although China has proposed the rural revitalization strategy to attract talents back to their hometowns, dividends in cities always attract waves of rural talents leaving their homes and taking root in cities. But this has a serious consequence. That is, only a small number of applied talents can be recognized by the masses in a village or town all over China. Such talent shortage and serious shortage of advantages will inevitably affect the development of science and technology, the process of agricultural industrialization and the development of rural economy. For talent revitalization, it is first required to improve the basic cultural quality of farmers. The current vocational training for farmers is generally mass training, which has helped traditional farmers at a low level of education improve their cultural quality to a certain extent. However, to complete the upgrade from traditional agriculture to modern agriculture, letting farmers read books and newspapers alone cannot meet their needs. Most farmers require professional agricultural skill training and technology training. The training content needs to be enriched. Cultivation objects can be roughly divided into two categories - the existing local agricultural laborers and urban residents willing to devote themselves to agriculture The two types of objects have quite different demands. It is difficult to achieve obvious results with the same training method for them. In particular, urban talents with certain capital, technology and management capabilities require policy and land support more. Therefore, the pertinence for training objects should be strengthened. The structure of rural construction talent teams is simple. In Village B, most of the production and technological development talents are mainly engaged in planting and at a low level of education. They generally lack theoretical and legal knowledge and knowledge about market economy. Some local talents have backward concepts and mainly seek stability in their view of wealth. They hardly participate in risky investment. In addition, few people know how to operate and manage. They are not good at communication with the outside world and stand still and are satisfied with current situation. This will inevitably lead to a low level of processing and trade of agricultural and sideline products and low added value of agricultural production, making it difficult to integrate with the big market.

\subsection{Inadequate functioning of the Party and the government}

According to the survey, although the current measures based on the strategy of rural revitalization taken by the committee of Village B are effective, the entire village starts from scratch each time when village cadres are changed and the previous measures are not continued. Therefore, villagers are restricted by many factors in their career development and have five hopes for government departments. First, they hope that the government can formulate long-term effective rural revitalization measures and ensure that the guarantee measures can be continued after change of cadres. Second, they hope that the government can coordinate relations, solve problems and help them in economy and technology. Third, they hope that the government can establish relevant training institutions so that they can learn the most advanced knowledge and technology. Fourth, they hope that the government can provide opportunities for external exchanges and organize local rural cooperatives or associations so that they can make innovations in exchanges. Fifth, they hope that the government can provide relevant skill qualifications so that they can work with certificates. However, Things go athwart. The 
government has hardly heard their voices, which has limited their careers.

\subsection{A Neglect of rural talent market planning and construction}

It is learnt that cadres of Village B begun to focus on its economic development and ecological environment after implementation of the rural revitalization strategy and established many effective development measures, which, however, has caused the lack of talents and the stagnation of the village economy. Compared with the rural talent market, the urban talent market is much more complete. Everyone can seek a career that suits their own development based on their own needs, which is also the main reason for the large influx of labor from the village to cities. In fact, the rural talent market is a medium for communication between local talents and enterprises. The lack of the talent market will inevitably affect the development of abilities of local talents, as a result of which they have to go to cities for development, and cause the lack of talents in enterprises.

\section{Reflections on the return of talents in Village B}

The government is a hard tool for rural revitalization, the leading role of which should be played to guide the return of talents. The rural revitalization strategy has become an important strategy leading China's rural reform in the new era since the $19^{\text {th }}$ National Congress of the Communist Party of China. The formulation of relevant laws and policies by the local government is in line with the wave of development of the times. The rural revitalization strategy of the Party has been embodied by the formulation of laws and regulations. The government is a hard tool for alleviating the problem of brain drain and implementing the strategy of rural revitalization. A series of long-term effective and systematic policies must be set up to support the return of talents. First, a local talent development policy system should be established. The government should make a scientific and reasonable development plan, clarify the guiding ideology, goals and measures for development and study and formulate rural development plans based on the requirements of economic and social development in combination with the laws and characteristics of talent growth in Village B. Second, an effective local talent management system should be established. A local talent development guiding institution under the responsibility of the Personnel Department should be set up under the leadership of the Organization Department, which should be managed jointly with science and technology, education, labor, agriculture and forestry departments to completely change the spontaneous and disorderly management of local talents and incorporate talents from multiple regions into the talent team for management. Meanwhile, qualifications and evaluation criteria of local talents should be clarified. Local talent filing and selection should be done well. They should be subjected to hierarchical dynamic management, regular assessment and the mechanism for survival of the fittest. Rural multi-level talents should be gradually incorporated into the scope of professional and technical talent management to enjoy relevant benefits. The formation of rural local talent groups should be promoted.

\subsection{Encouraging talents to return to their hometowns and improving the overall strength of the village through talent training}

Talents are the key to rural revitalization. In terms of system recruitment, the state has further expanded the recruitment of township civil servants in recent years. The recruitment office of Village $B$ can also issue several recruitment announcements to fill the vacancies in public positions at this stage. In terms of social recruitment, it is necessary to create a good atmosphere for local talent development and entrepreneurship, give spiritual and material rewards to local talents who have made obvious contributions to rural economic development and prioritize agricultural development assistance projects, agricultural loans and other advanced technical equipment information. We can publicize advanced talents who play an exemplary role in the countryside by information transfer means of traditional and emerging media to improve the social influence of rural native talents in the village, give play to their leading role in the talent team, drive the ability of local talents to get rich first and lead others to be rich and provide one-on-one special counseling, and improve the comprehensive strength of rural talents.

\subsection{Improving rural educational measures and customizing relevant institutions for exclusive rural education}

It is necessary to improve the cultural soft power of villagers, including not only the professional technical level, but also their ideology. Education goals can be clarified through "on-demand teaching" rather than the traditional "wide" educational mode based on the characteristics and needs of rural areas, which can help to improve the accuracy of cultivation and increase the enthusiasm of farmers. Specialized agricultural schools also have the advantages of specialized high-level teachers educational resources and technical research that traditional educational institutions do not have, which can promote the improvement of the comprehensive quality and hard power of professional farmers. Like in traditional academic education, they can be approved for graduation and receive the corresponding certificate only after completing the specified study and being qualified. The reliability of vocational certificates of farmers can be improved.

\subsection{Driving the complementation between economic development and talent training based on industrial driving}

First, we should further strengthen industrial development, 
provide support in terms of capital, technology and production materials and train some professional breeding talents to enable them to master the technology in accordance with the requirements of building a new socialist countryside; develop characteristic industries and allow such talents to become leaders of rural prosperity and disseminators of the latest scientific and technological knowledge and play an exemplary and leading role. Second, we should focus on the construction of industrial bases and cultivate practical technologies in various forms in rural areas. To promote the development of agricultural industrialization and the construction of a new socialist countryside, it is required to establish and improve a multiregional talent training mechanism, update, enrich and deepen the knowledge of talents in multiple regions continuously and improve the comprehensive quality of villagers.

\subsection{Promoting the convergence and integration of rural local talents with association linkage as a link}

Party organizations and relevant departments should ride on the momentum to implement various measures for the rural revitalization strategy, advance the development of various industries and associations in the countryside, establish planting and breeding industry associations and support association members in technical and information exchanges so that they can continue exchanges and collisions of ideas, thus promoting rural development. The government should also play a coordinating role and formulate long-term effective sustainable development measures. The implementation of the rural revitalization strategy not only is a verbal expression, but also requires step-by-step efforts to implement each measure and policy. The Party and the government should exert their own strengths and seek common development so as to change the scattered state of many local people and give play to the advantages of local talent groups.

\subsection{Relying on market pull and creating a good talent exchange environment}

The rural talent market is a key hub to promote the exchange of talents between cities and rural areas. The main ways and important means of rural talent allocation are to optimize the structure of talent resources and select and allocate various types of talents. To prevent the brain drain of Village $B$, it is key to incorporating the construction of the rural talent market into the plan, actively exploring the field of talent market operation, improving the development strategy of talent supply, accelerating the standardized operation of the market and establishing a talent workstation under independent management of the township. It is necessary to combine the county-level talent market with township talent workstations to form a top-down systemic network, establish an operational framework that suits its own talent development and build a development base for local talents in rural areas. Meanwhile, it is also required to combine the county and township talent markets, adhere to the principle of service quality first, provide various talents, technologies and information services to be applied to the primary and secondary industries in a timely manner, supply talents continuously for enterprises, and provide talent support for Village B to achieve the goal of building a new socialist countryside in an all-round way.

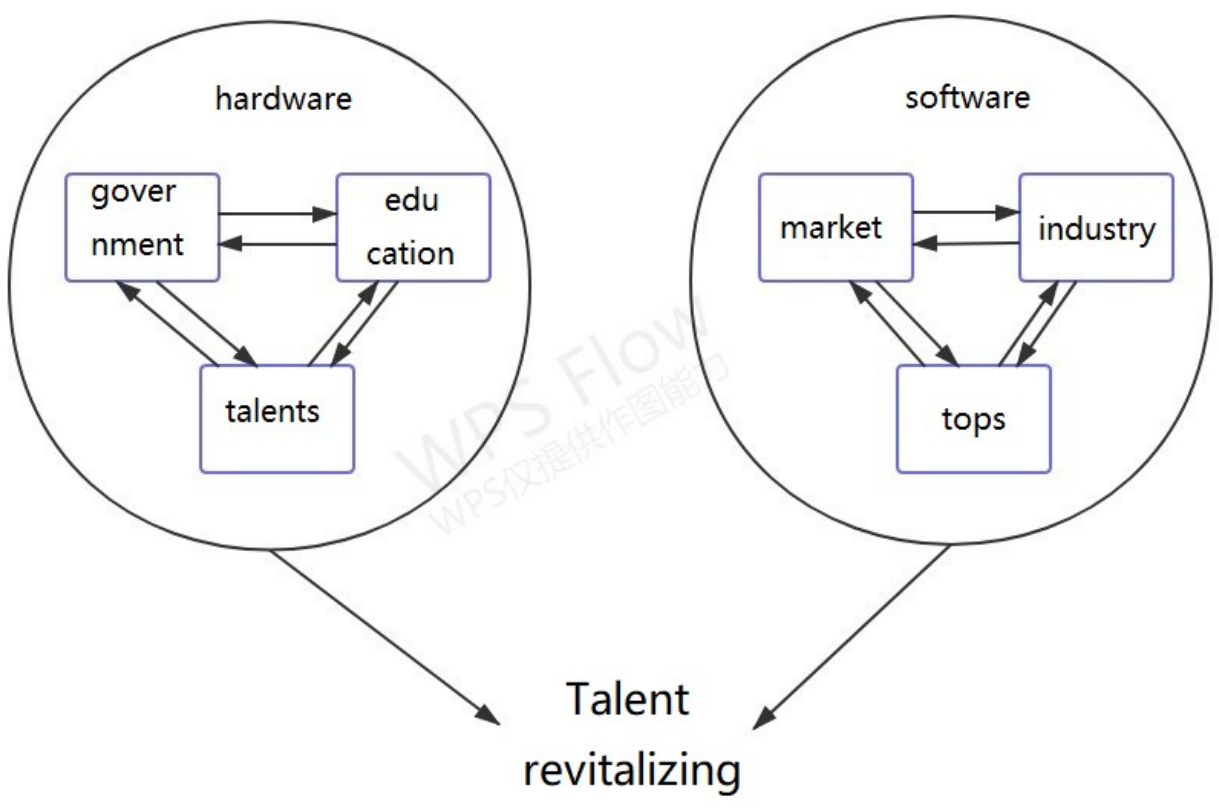

Figure 9: Model diagram of the return of talents in Village B

To make the talent revitalization strategy play its real role, measures for the return of talents can be divided into two aspects as shown in Figure 9. One is compulsory reform. The emphasis of brain drain should be seized 
through analysis of problems regarding the government, education and talents and relevant systematic and professional policies and measures should be established to address the main contradiction of brain drain quickly and accurately. The other is long-term reform. Talents should be input continuously to Village B through interactive coordination of third parties such as the market, industry and association so as to enrich the rural talent market and create a good talent exchange environment.

\section{References:}

1. Li Shouhan, Liu Tao. Mirror of Japanese Rural Revitalization [J]. Shandong Agricultural Sciences, 2020, 052(005):157-165.

2. Xu Xue. Experience of and Reference from Japan's Rural Revitalization Movement $[\mathrm{J}]$. Journal of Hunan Agricultural University (Social Science), 2018, 19(05):68-73.

3. Yi Ming. Opinions of the Central Committee of the Communist Party of China and the State Council on the Implementation of Rural Revitalization Strategy [J]. Gazette of the State Council of the People's Republic of China, 2018(5).

4. Pu Shi, Sun Wenying. Research on Rural Talent Construction Policy under the Background of Implementing Rural Revitalization Strategy [J]. Chinese Public Administration, 2018, 000(011):90-93.

5. Qian Zaijian, Wang Jiayan. "Talents Going to the Countryside": New County Sage Helping Rural Revitalization [J]. Chinese Public Administration, 2019, 000(002): 92-97.

6. Zhou Lingling. Impact of Population Mobility on Rural Social Governance and Countermeasures [J]. Development Research, 2020, 000(001):78-84.

7. Liu Chang'e, Xie Wei. Research on Problems of and Countermeasures for Talent "Return" under New Rural Revitalization Strategy [J]. Journal of Hunan Institute of Socialism, 2018, (5).

8. Wang Yudong, Chen Huitao. Cultivation of New Professional Farmers through School-Village Cooperation - Based on Path Thinking of Rural Talent Revitalization [J]. Journal of Qingdao Agricultural University (Social Science), 2018, v.30; No.94(03):16-20.

9. Wang Yuanyi, Hu Yanli. Talent Training Orientation and Mechanism Construction for Rural Vocational Education under the Background of Rural Industry Revitalization $[\mathrm{J}]$. Journal of Wuhan Polytechnic, 2021, 20(01): 21-25.

10. Lu Pingkuan. Thoughts on the Development of Rural Native Talents [J]. Journal of Guangxi University for Nationalities (Philosophy and Social Science), 2008(S1):71-73.

11. Liu Xiaoming. Path Selection of Talent Support for Rural Revitalization from the Perspective of Big Data [J]. Journal of Heze University, 2019(3).

12. Zhao Quanmin, Liu Jingbei. Reversal between the
Goal of New Countryside Construction and the Reality: Dilemma of Intellectual Support of Rural Talents [J]. Contemporary World and Socialism, 2008, 000(001):122-125. 